\title{
Effects of three-dimensional collagen scaffolds on the expression profiles and biological functions of glioma cells
}

\author{
WEI JIA $^{1-3}$, XINGJUN JIANG ${ }^{4 *}$, WEIDONG LIU ${ }^{1-3}$, LEI WANG $^{1-3}$, BIN ZHU $^{1-3}$, HECHENG ZHU $^{3}$, \\ XINGDONG LIU $^{3}$, MEIZUO ZHONG ${ }^{3}$, DAN XIE ${ }^{5}$, WEI HUANG ${ }^{1,2}$, WENTING JIA $^{1,2}$, SHASHA LI ${ }^{1,2}$, \\ XUXU LIU ${ }^{1,2}$, XIANG ZUO ${ }^{1,2}$, DAMEI CHENG ${ }^{1,2}$, JIANWU DAI $^{6^{*}}$ and CAIPING REN ${ }^{1-3^{*}}$

\begin{abstract}
${ }^{1}$ The Key Laboratory of Carcinogenesis of the Chinese Ministry of Health and The Key Laboratory of Carcinogenesis and Cancer Invasion of the Chinese Ministry of Education, Xiangya Hospital, Central South University, Changsha, Hunan 410008;

${ }^{2}$ Cancer Research Institute, Collaborative Innovation Center for Cancer Medicine, School of Basic Medical Science,

Central South University, Changsha, Hunan 410078; ${ }^{3}$ Changsha Kexin Cancer Hospital, Changsha, Hunan 410205;

${ }^{4}$ Department of Neurosurgery, Xiangya Hospital, Central South University, Changsha, Hunan 410008; ${ }^{5}$ State Key Laboratory of Oncology in South China, Collaborative Innovation Center for Cancer Medicine, Sun Yat-sen University Cancer Center,

Guangzhou, Guangdong 51006; ${ }^{6}$ State Key Laboratory of Molecular Developmental Biology, Institute of

Genetics and Developmental Biology, Chinese Academy of Sciences, Beijing 100190, P.R. China
\end{abstract}

Received November 22, 2017; Accepted March 12, 2018

DOI: $10.3892 /$ ijo.2018.4330

\begin{abstract}
Three-dimensional (3D) culture has been increasingly used to investigate tumor cell biology for improved simulation of the natural developing environment. However, the way in which $3 \mathrm{D}$ culture affects the gene expression and biological functions of glioma cells remains to be fully elucidated. In the present study, 3D culture environments were established using collagen scaffolds with different pore sizes, followed by the comparison of gene expression profiles and associated biological functions of glioma cells, including the U87, U251 and HS683 cell lines, in 3D collagen scaffolds with conventional two-dimensional (2D) cultured cells. Finally, the possible signaling pathways regulating these differences were investigated. It was found that the $3 \mathrm{D}$ collagen scaffold culture upregulated the expression of genes associated with stemness, cell cycle, apoptosis, epithelia-mesenchymal transition, migration, invasion and glioma malignancy, and induced the
\end{abstract}

Correspondence to: Dr Caiping Ren, The Key Laboratory of Carcinogenesis of the Chinese Ministry of Health and The Key Laboratory of Carcinogenesis and Cancer Invasion of the Chinese Ministry of Education, Xiangya Hospital, Central South University, 87 Xiangya Road, Changsha, Hunan 410008, P.R. China

E-mail: rencaiping@csu.edu.cn

Dr Jianwu Dai, State Key Laboratory of Molecular Developmental Biology, Institute of Genetics and Developmental Biology, Chinese Academy of Sciences, 1 West Beichen Road, Chaoyang, Beijing 100190, P.R. China

E-mail: jwdai@genetics.ac.cn

"Contributed equally

Key words: three-dimensional culture, glioma, malignancy, stemness, invasion corresponding functional changes. Apoptotic pathways, the Wnt pathway, Sonic Hedgehog pathway and Notch pathway, may be involved in the regulation of these changes. The aperture size of the collagen-scaffold did not appear to affect the gene expression or functions of the glioma cells. The results of the study suggested that the 3D collagen scaffold enhanced the malignancy of glioma cells and may be a promising in vitro platform for investigations of glioma.

\section{Introduction}

Glioma is the most common and life-threatening type of brain tumor (1). Even following surgery, radiation and chemotherapeutic treatments, the majority of patients with glioma succumb to mortality within 2 years of diagnosis $(2,3)$. How to improve the efficacy of clinical diagnosis and treatment for glioma has become the focus of investigations on glioma.

Traditional two-dimensional (2D) cell culture systems are often used to assess the sensitivity of tumor cells to radiotherapy and chemotherapy, and guide the clinical treatments. However, 2D cultured cells perform poorly and are not suitable for investigating solid tumors $(4,5)$, as they do not accurately reproduce tissue architecture or have interactions between cells and their microenvironment. This leads to deviations in drug sensitivities between in vitro tests and in vivo clinical evaluations. Therefore, a novel research model is crucial for the development of effective anti-glioma therapeutics.

Three-dimensional (3D) cell culture systems, including sphere $(6,7)$ and material culture (8-12) have been applied for several type of tumor, as they better simulate the native tumor microenvironment and provide more accurate drug efficacy analysis. The biomaterials used to establish 3D culture system include poly (lactic-co-glycolic) acid, chitosan, alginate, Matrigel and collagen. Among these, collagen is an ideal biomaterial for 3D scaffolds, as it is the main component of the 
extracellular matrix (ECM) in connective tissues, and has low antigenicity. The commonly applied biomaterials in studies of glioma are Matrigel and hydrogel, and their application is mainly focused on detection of the sensitivities of co-cultured tumor cells to radiation and drugs (13-25). There have been few reports on collagen scaffold culture in glioma, and its effects on whole gene expression profiles and the functions of glioma cells remain to be fully elucidated.

In the present study, glioma cells (U87, U251 and HS683) were cultured in 3D collagen scaffolds with different porediameters, and the cell morphology, gene expression profiles, biological functions and associated signaling pathways of the $3 \mathrm{D}$ cultured cells were compared with those of $2 \mathrm{D}$ monolayer cultured cells.

\section{Materials and methods}

Preparation of $3 D$ collagen scaffolds. The collagen scaffolds were prepared as previously described (26). According to the pore diameter, they were subdivided into scaffold A (diameter, 30-50 $\mu \mathrm{m}$ ) and scaffold B (diameter, 70-100 $\mu \mathrm{m}$ ) types.

Cell culture. The 2D culture was performed as follows: Three glioma cell lines (U87, U251 and HS683 cells) were purchased from Xiangya Central Laboratory (Xingya, China). The U87 and HS683 cells were grown and maintained in Dulbecco's modified Eagle's medium (DMEM; Sigma-Aldrich; EMD Millipore, Billerica, MA, USA), and the U251 cells were in RPMI-1640 medium (Sigma-Aldrich; EMD Millipore). Both media were supplemented with $10 \%$ fetal bovine serum (Biological Industries, Kibbutz Beit Haemek, Israel), $100 \mathrm{U} / \mathrm{ml}$ penicillin and $100 \mathrm{mg} / \mathrm{ml}$ streptomycin (termed complete medium). All the cells were cultured in cell culture flasks at $37^{\circ} \mathrm{C}$ with $5 \% \mathrm{CO}_{2}$.

The 3D-culture was performed as follows: Following immersion in homologous cell culture mediums for $24 \mathrm{~h}$ at $37^{\circ} \mathrm{C}$, the collagen scaffolds were loaded with cell suspensions ( $1 \times 10^{5}$ cells in $20 \mu \mathrm{l}$ medium per scaffold) and maintained at $37^{\circ} \mathrm{C}$ for $4 \mathrm{~h}$; every scaffold with seeded cells was then transferred to one well of a 12-well cell culture plate containing $2 \mathrm{ml}$ complete medium, which was replaced every 2 days. The process of harvesting cells from the 3D collagen scaffold was performed mainly through trypsin digestion. In brief, every scaffold with cells was washed with phosphate buffer solution (PBS) three times, and then submerged in $0.25 \%$ trypsin (Invitrogen; Thermo Fisher Scientific, Inc., Waltham, MA USA) at $37^{\circ} \mathrm{C}$ for $10 \mathrm{~min}$. During the digestion, the scaffold was blown using pipette tips 2-3 times. The digestion was terminated by the complete medium which contains the fetal bovine serum. The whole process was repeated once to harvest as many cells as possible. The twice-digested fluid was collected, and the supernatant was discarded following centrifugation (300 x g, $5 \mathrm{~min}$, room temperature). The resulting pure cells were used for the subsequent experiments.

Cell morphology analysis. Cell morphology was observed via FDA (Sigma-Aldrich; EMD Millipore) staining and hematoxylin and eosin (H\&E; Sigma-Aldrich; EMD Millipore). For the FDA staining, the scaffolds with cells cultured for 1,5 and 10 days were washed with PBS three times, then submerged in
FDA solution (1\%FDA in PBS) for $1 \mathrm{~min}$, and washed twice with PBS. The stained scaffolds were observed under the fluorescent inverted phase contrast microscope (Nikon Imaging Japan Inc., Tokyo, Japan; cat. no. Elipse E2000-S). For the $\mathrm{H} \& \mathrm{E}$ staining, the three glioma cell lines growing on glass coverslips were examined. Scaffolds on day 10 were fixed in $4 \%$ paraformaldehyde, embedded in paraffin, cut into $5-\mu \mathrm{m}$ sections and stained with $H \& E$.

Cell proliferation assay. The three glioma cell lines were seeded at a density of $1 \times 10^{5}$ cells/scaffold or $3 \times 10^{4}$ cells/well in a 6 -well plate, respectively. Following culture for 1, 5 and 10 days, every scaffold or well $(n=3)$ was digested with $0.25 \%$ trypsin, following which the cell numbers were counted. Cell count was determined as a relative value, and the number of seeded cells was set as 1 .

RNA isolation and reverse transcription-quantitative polymerase chain reaction ( $R T-q P C R)$ analysis. Total mRNA was isolated from the $2 \mathrm{D}$ and $3 \mathrm{D}$ (on day 10) cultured cells using TRIzol $^{\mathrm{TM}}$ reagent (Invitrogen; Thermo Fisher Scientific, Inc.), following the manufacturer's protocol. The RT-qPCR analysis was performed as previously described (27). Reverse transcription (RT) was carried out with $2 \mu \mathrm{g}$ total RNA per $20 \mu \mathrm{l}$ reaction using the 5X All-In-One MasterMix (ABM, Richmond, BC, Canada). qPCR was performed with the CFX96 Real-Time PCR detection system (Bio-Rad Laboratories, Inc., Hercules, CA, USA; cat. no. 185-5195) using AceQ ${ }^{\circledR}$ qPCR SYBR ${ }^{\circledR}$ Green Master mix (Vazyme, Piscataway, NJ, USA). The final volume of the reaction mix was $25 \mu 1$, consisting of AceQ qPCR SYBR-Green Master mix (2X) $10 \mu \mathrm{l}, 0.2 \mu \mathrm{M}$ of each specific forward and reverse primer, the resulting cDNA $1 \mu 1$ and sterile purified water. Amplifications were done under standard conditions $\left(5 \mathrm{~min}\right.$ at $95^{\circ} \mathrm{C}$ followed by 40 cycles of $10 \mathrm{sec}$ at $95^{\circ} \mathrm{C}$ and $30 \mathrm{sec}$ at $60^{\circ} \mathrm{C}$ ). Sequence-specific primers were quoted from an official website 'PrimerBank' (http:// pga.mgh.harvard.edu/primerbank/) for the indicated genes (Tables I and II). All reactions were performed in triplicate, and relative changes in transcript level normalized by $\beta$-actin mRNA were calculated by the $\Delta \Delta \mathrm{Ct}$ method (28).

Western blot analysis. Western blot analysis was performed in accordance with the previously described method (29). In brief, on day 10 , the cells cultured in $2 \mathrm{D}$ or $3 \mathrm{D}$ environments were lysed in RIPA (Beyotime Institute of Biotechnology, Haimen, China) for $30 \mathrm{~min}$ and total proteins were obtained. Following high-speed centrifugation $\left(12,000 \times \mathrm{g}, 30 \mathrm{~min}, 4^{\circ} \mathrm{C}\right)$, the proteins were denatured, and the proteins $(40 \mu \mathrm{g})$ were loaded and separated by $6-12 \%$ SDS-PAGE gels. The samples were transferred onto a PVDF membrane (EMD Millipore) followed by blocking with $5 \%$ milk in TBST and then immunoblotting with target primary antibodies and anti- $\beta$-actin antibody overnight at $4^{\circ} \mathrm{C}$, respectively. Finally, the Gel Imaging system (Bio-Rad Laboratories, Inc.; cat. no. Universal Hood II, Chemi, $\mathrm{XR}+, \mathrm{XRS}+$ ) was used to visualize the protein bands following incubation with corresponding peroxidase-conjugated anti-IgG antibody (1:40,000, A0545 or A9044, Sigma-Aldrich; EMD Millipore) for $1 \mathrm{~h}$ at room temperature. The visualisation reagent was Luminata ${ }^{\mathrm{TM}}$ Crescendo Western HRP Substrate (EMD Millipore). The primary antibodies used in the present study included the following: Anti-CD133 (1:500, 18470-1-AP), 
Table I. Primer sequences used for reverse transcriptionquantitative polymerase chain reaction amplification of genes related to stemness and cell cycle.

\begin{tabular}{|c|c|}
\hline Gene & Primer sequence $\left(5^{\prime}-3^{\prime}\right)$ \\
\hline$C D 133$ & $\begin{array}{l}\text { F: ATTGACTTCTTGGTGCTGTTGA } \\
\text { R: GATGGAGTTACGCAGGTTTCTC }\end{array}$ \\
\hline Nestin & $\begin{array}{l}\text { F: CTTGCCTGCTACCCTTGAGAC } \\
\text { R: GTTTCCTCCCACCCTGTGT }\end{array}$ \\
\hline Oct4 & $\begin{array}{l}\text { F: TATTCAGCCAAACGACCATCT } \\
\text { R: TCAGCTTCCTCCACCCACTT }\end{array}$ \\
\hline Sox 2 & $\begin{array}{l}\text { F: TGTCAAGGCAGAGAAGAGAGTG } \\
\text { R: GCCGCCGATGATTGTTATTAT }\end{array}$ \\
\hline Nanog & $\begin{array}{l}\text { F: CCCCAGCCTTTACTCTTCCTA } \\
\text { R: CCAGGTTGAATTGTTCCAGGTC }\end{array}$ \\
\hline$c-M y c$ & $\begin{array}{l}\text { F: GGCTCCTGGCAAAAGGTCA } \\
\text { R: CTGCGTAGTTGTGCTGATGT }\end{array}$ \\
\hline MSII & $\begin{array}{l}\text { F: CCAACCGGCACCGAGGGTTC } \\
\text { R: GCTGAGCCCGTTGGCGACAT }\end{array}$ \\
\hline MSI2 & $\begin{array}{l}\text { F: ACGACTCCCAGCACGACC } \\
\text { R: GCCAGCTCAGTCCACCGATA }\end{array}$ \\
\hline BMI-1 & $\begin{array}{l}\text { F: CGTGTATTGTTCGTTACCTGGA } \\
\text { R: TTCAGTAGTGGTCTGGTCTTGT }\end{array}$ \\
\hline$C C N A$ & $\begin{array}{l}\text { F: TGGAAAGCAAACAGTAAACAGCC } \\
\text { R: GGGCATCTTCACGCTCTATTT }\end{array}$ \\
\hline$C C N B$ & $\begin{array}{l}\text { F: AATAAGGCGAAGATCAACATGGC } \\
\text { R: TTTGTTACCAATGTCCCCAAGAG }\end{array}$ \\
\hline$C C N D$ & $\begin{array}{l}\text { F: CAATGACCCCGCACGATTTC } \\
\text { R: CATGGAGGGCGGATTGGAA }\end{array}$ \\
\hline CCNE & $\begin{array}{l}\text { F: GCCAGCCTTGGGACAATAATG } \\
\text { R: CTTGCACGTTGAGTTTGGGT }\end{array}$ \\
\hline$p 21$ & $\begin{array}{l}\text { F: TGTCCGTCAGAACCCATGC } \\
\text { R: AAAGTCGAAGTTCCATCGCTC }\end{array}$ \\
\hline$p 27$ & $\begin{array}{l}\text { F: ATCACAAACCCCTAGAGGGCA } \\
\text { R: GGGTCTGTAGTAGAACTCGGG }\end{array}$ \\
\hline$\beta$-actin & $\begin{array}{l}\text { F: CCTGTACGCCAACACAGTGC } \\
\text { R: ATACTCCTGCTTGCTGATCC }\end{array}$ \\
\hline
\end{tabular}

F, forward; R, reverse; Oct4, octamer-binding transcription factor 4; Sox2, SRY-Box 2; MSI, Musashi RNA binding protein; $C C N$, cyclin.

anti-Nestin (1:500, 19483-1-AP), anti-octamer-binding transcription factor 4 (Oct4) (1:500, 11263-1-AP), anti-SRY-Box 2 (Sox2) (1:500, 11064-1-AP), anti-Nanog (1:500, 14295-1-AP), anti-c-Myc (1:500, 10828-1-AP), anti-Musashi RNA binding protein (MSI)1 (1:500, 27185-1-AP), anti-MSI2 (1:500, 107701-AP), anti-cyclin (CCN)A1 (1:500, D151775), anti-CCNB1 (1:500, 55004-1-AP), anti-CCND1 (1:500, 60186-1-Ig), anti-CCNE1 (1:500, 11554-1-AP), anti-p21 (1:500, 103551-AP), anti-p27 (1:500, 26714-1-AP), anti-N-cadherin (1:400, BA0673), anti-vimentin (1:400, BM0135), anti-matrix metalloproteinase (MMP)1 (1:400, BM4305), anti-MMP2 (1:400, BM4075), anti-MMP3 (1:300, BM4074), anti-MMP7 (1:300, PB0070), anti-glial fibrillary acidic protein (GFAP) (1:500,
Table II Primer sequences used for reverse transcriptionquantitative polymerase chain reaction amplification of genes related to epithelial-mesenchymal transition, migration, invasion and glioma malignancy.

\begin{tabular}{ll}
\hline Gene & \multicolumn{1}{c}{ Primer sequence (5'-3') } \\
\hline$N$-cadherin & F: AGCCAACCTTAACTGAGGAGT \\
Rimentin & F: GGCAAGTTGATTGGAGGGATG \\
& R: CATTTCACGCATCTGGCGTTC \\
$M M P 1$ & F: CTCTGGAGTAATGTCACACCTCT \\
& R: TGTTGGTCCACCTTTCATCTTC \\
$M M P 2$ & F: GATACCCCTTTGACGGTAAGGA \\
& R: CCTTCTCCCAAGGTCCATAGC \\
$M M P 3$ & F: CTGGACTCCGACACTCTGGA \\
R: CAGGAAAGGTTCTGAAGTGACC & F: GAGTGAGCTACAGTGGGAACA \\
$M M P 7$ & R: CTATGACGCGGGAGTTAACAT \\
FFAP & F: AGGTCCATGTGGAGCTTGAC \\
& R: GCCATTGCCTCATACTGCGT \\
FGFR & F: AGGCACGAGTAACAAGCTCAC \\
Ki67 & R: ATGAGGACATAACCAGCCACC \\
& F: GCCTGCTCGACCCTACAGA \\
& R: GCTTGTCAACTGCGGTTGC \\
\hline
\end{tabular}

F, forward; R, reverse; MMP, matrix metalloproteinase; GFAP, glial fibrillary acidic protein; EGFR, epidermal growth factor receptor.

23935-1-AP), anti-epidermal growth factor receptor (EGFR) (1:500, 22542-1-AP), anti-Ki67 (1:500, BS1454), anti-p53 (1:500, 10442-1-AP), anti-programmed death-ligand 1 (PDL1) (1:500, 17952-1-AP), and anti-Livin (1:500, 27543-1-AP), the Apoptosis Antibody Sampler kit [including caspase (Cas)3, 7 and 9, PARP] (1:1,000, \#9915), Notch Isoform Antibody Sampler kit $(1: 1,000, \# 3640)$, anti-Wnt3a (1:400, BA2628-2), anti-Wnt5a (1:400, BA2839), anti-SHH (1:500, 20697-1-AP) and anti- $\beta$-actin $(1: 3,000$, A5441). With the exception of anti-caspase 9, anti-vimentin, anti-p53, CCND1 and anti- $\beta$-actin, which were mouse monoclonal antibodies, the primary antibodies mentioned above were rabbit polyclonal antibodies. The Apoptosis Antibody Sampler kit and the Notch Isoform Antibody Sampler kit were purchased from Cell Signaling Technology, Inc. (Danvers, MA, USA), and anti- $\beta$-actin primary antibody was from Sigma-Aldrich; EMD Millipore. The anti-Ki67 primary antibody was from Bioworld Technology, Inc. (St. Louis Park, MN, USA), and the anti-CCNA1 primary antibody was from BBI Life Sciences Corp. (Shanghai, China). The anti-N-cadherin, anti-vimentin, anti-MMP1, anti-MMP2, anti-MMP3, anti-MMP7, Wnt3a and Wnt5a primary antibodies were purchased from Boster Biological Technology, Ltd. (Wuhan, Hubei, China), and the remainder of the primary antibodies were from ProteinTech Group, Inc. (Chicago, IL, USA).

Colony formation assay. For the colony formation assays, glioma cells from the different culture models were plated at 


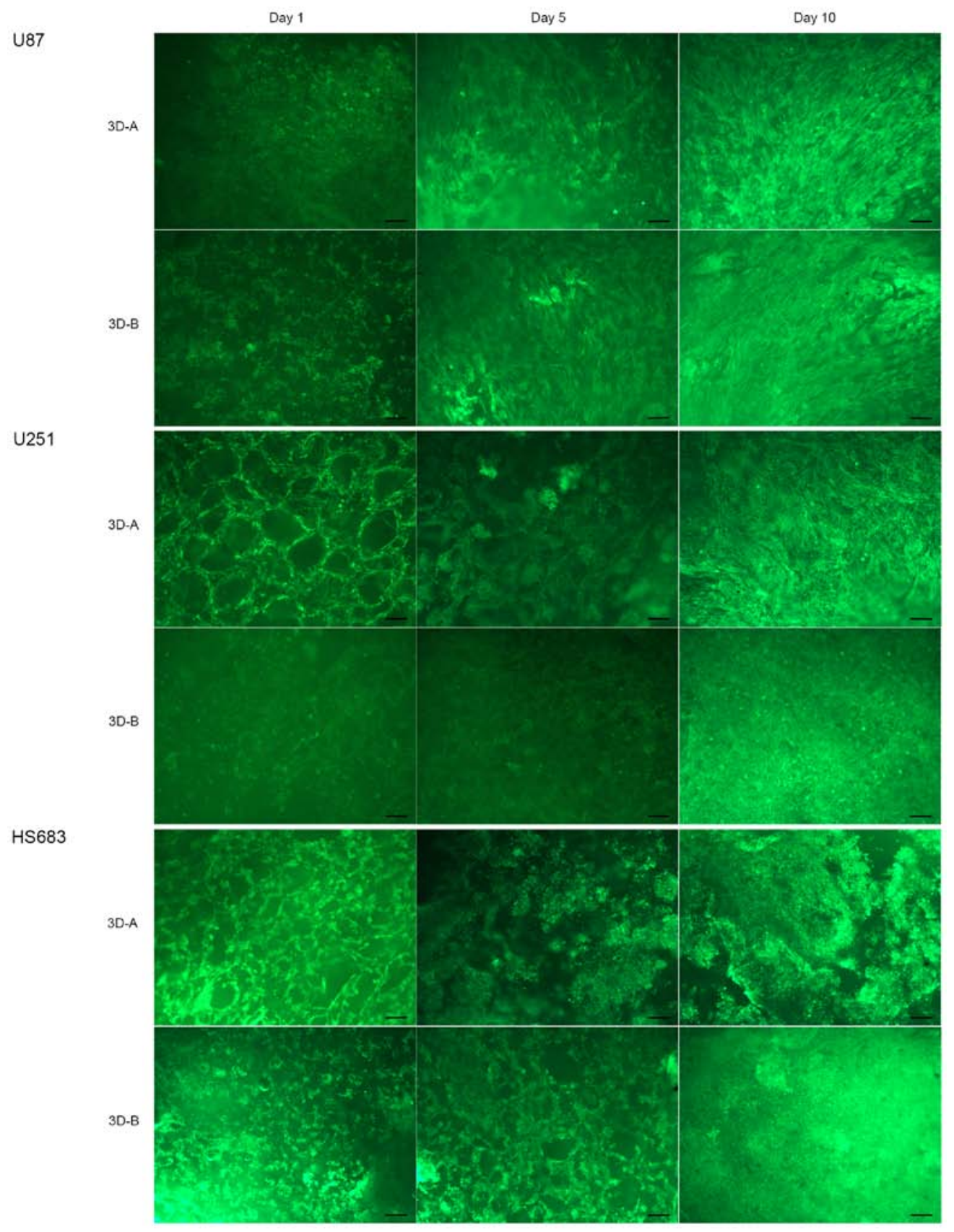

Figure 1. Morphology of three glioma cell lines (U87, U251 and HS683 cells) in different collagen scaffolds by FDA staining on days 1,5 and 10. All three cell types adhered to the scaffolds and grew along the skeleton. With the increase of culture duration, the numbers of the cells also increased. These cells appeared stereoscopic and formed a multi-layer structure (scale bar, $100 \mu \mathrm{m}$ ). 3D, three-dimensional; 2D, two-dimensional.

1,000 cells/well in different complete medium in 6-well plates, and were allowed to form colonies for 10 days. The colonies were fixed with $4 \%$ paraformaldehyde for $15 \mathrm{~min}$ and stained with $0.4 \%$ crystal violet for $30 \mathrm{~min}$. Colonies containing $>50$ cells were counted manually using the inverted phase contrast microscope mentioned above.

Wound-healing assay. A wound-healing assay was performed according to a previously described protocol (30). The glioma cells from the different culture models were plated in 6-well plates. On reaching $95 \%$ confluence, the cell monolayers were wounded with a P-200 pipette tip, and the wounded monolayers were gently washed three times with PBS; medium containing $2 \%$ FBS was then added for further incubation. Images were captured at 0,12 and $24 \mathrm{~h}$, and the distances between the two wound edges were scaled for three positions at different time-points. The distances at 0,12 and $24 \mathrm{~h}$ were counted as $\mathrm{d} 0, \mathrm{~d} 1$ and $\mathrm{d} 2$, respectively. Relative width $=(\mathrm{d} 1$ or $\mathrm{d} 2-\mathrm{d} 0) / \mathrm{d} 0$.

Transwell invasion assay. To examine the invasive capacity of the glioma cells, Transwell invasion assays were performed using 24-well MILLI cell hanging cell culture inserts $(8 \mathrm{~mm}$ PET; EMD Millipore) coated with Matrigel matrix gel (BD Biosciences, Franklin Lakes, NJ, USA) according to the manufacturer's protocol. Cells from the different culture models were suspended in serum-free medium and $5 \times 10^{4}$ cells were added into the upper chamber. Following incubation for $48 \mathrm{~h}$, the cells on the underside of the membrane were fixed 


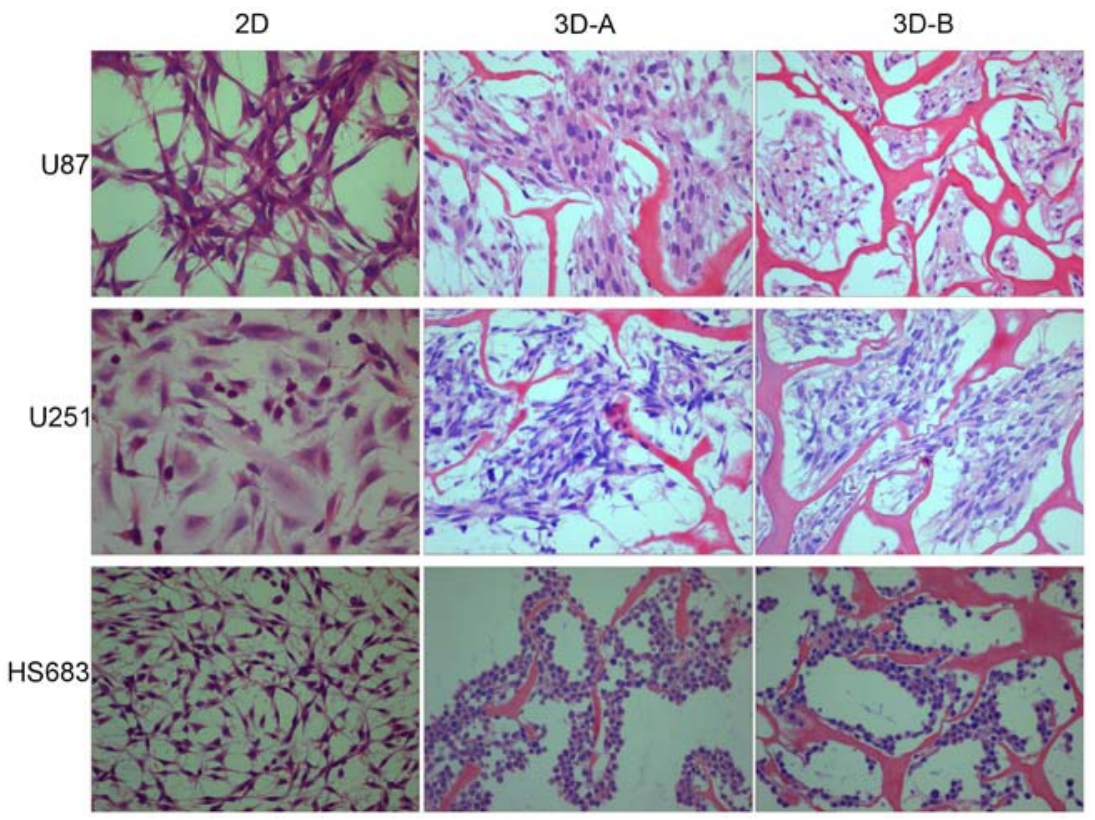

Figure 2. Morphology of glioma cells on 2D plates and in 3D scaffolds by hematoxylin and eosin staining. For the 2D groups, cells grown on coverslips were used. For 3D groups, the slides of 3D scaffolds on day 10 were used. Glioma cells in 2D culture were fusiform or polygonal, flat and epithelioid or fibroblastlike, but those in 3D scaffolds grew as small, round or ovoid conglomerate cells. The latter also exhibited trachychromatic and heteromorphous nuclei (magnification, x200). 3D, three-dimensional; 2D, two-dimensional.

U87

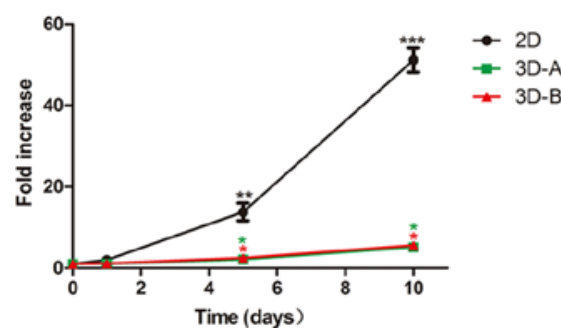

U251

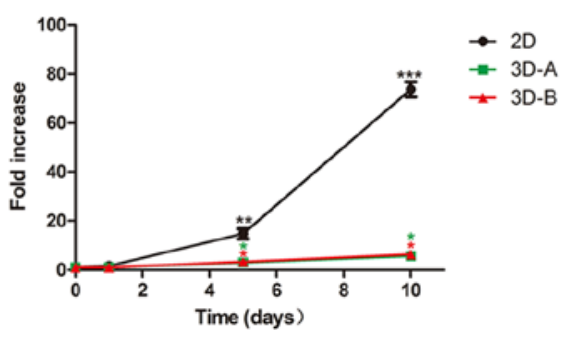

HS683

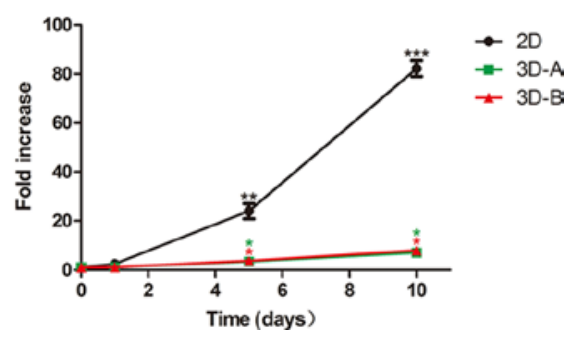

Figure 3. Numbers of the three types of glioma cell cultured under 2D and 3D conditions on days 1,5 and 10 determined by cell counting. Cell multiplication is expressed as a relative value, and the number of seeded cells at 0 day was set as 1 . ${ }^{*} \mathrm{P}<0.05,{ }^{* *} \mathrm{P}<0.01$ and ${ }^{* * * *} \mathrm{P}<0.001$, compared with day 1 . All the three types of glioma cell showed a lag phase of 1-5 days and an exponential increase between 5 and 10 days. The cells grew more slowly in the 3D scaffolds, compared with those in the 2D monolayer cultures. There was no statistically significant difference between the scaffold A group and scaffold B group for each type of cell. 3D, three-dimensional; 2D, two-dimensional.

with $4 \%$ paraformaldehyde and stained with $0.1 \%$ crystal violet solution. The cells attached to the lower surface were counted under a microscope (Nikon, Tokyo, Japan) at x400 magnification in six randomly selected fields.

Statistical analysis. Data are presented as the mean \pm standard deviation of at least three independent experiments. Statistical significance was determined using one-way analysis of variance (ANOVA) with Tukey's multiple comparisons test performed in IBM SPSS Statistics 24.0 (SPSS, Inc., Chicago, IL, USA). $\mathrm{P}<0.05$ was considered to indicate a statistically significant difference.

\section{Results}

Cell morphology and proliferation. Firstly, the present study examined the morphology of the three glioma cell lines (U87-MG, U251 and HS683) in the different collagen scaffolds by FDA staining on days 1, 5 and 10. As shown in Fig. 1, all three cell lines adhered to the scaffolds and grew along the skeleton. With the increase of culture duration, the numbers of cells also increased. These cells appeared stereoscopic and formed a multilayer structure. The shape of the 3D-cultured cells on day 10 was compared with those on the $2 \mathrm{D}$ culture plates by $\mathrm{H} \& \mathrm{E}$ staining. As shown in Fig. 2, the glioma cells in 2D culture were fusiform or polygonal, flat and epithelioid or fibroblast-like, whereas those in the 3D scaffolds grew as small, round or ovoid conglomerate cells. The latter also exhibited trachychromatic and heteromorphous nuclei. Among the three cell lines, the morphological change of the U87 cells was the most marked. The U87 and U251 cells gathered to form masses, and more HS683 cells grew along the skeleton. Between scaffold A and scaffold B, cells in the latter exhibited increased variance.

The present study then examined the number of cells in the three glioma cell lines cultured under 2D and 3D conditions on days 1,5 and 10 by cell number counting. For all three glioma cell lines, similar proliferation curves were observed between the 3D-cultured cells and 2D cells (Fig. 3), which 

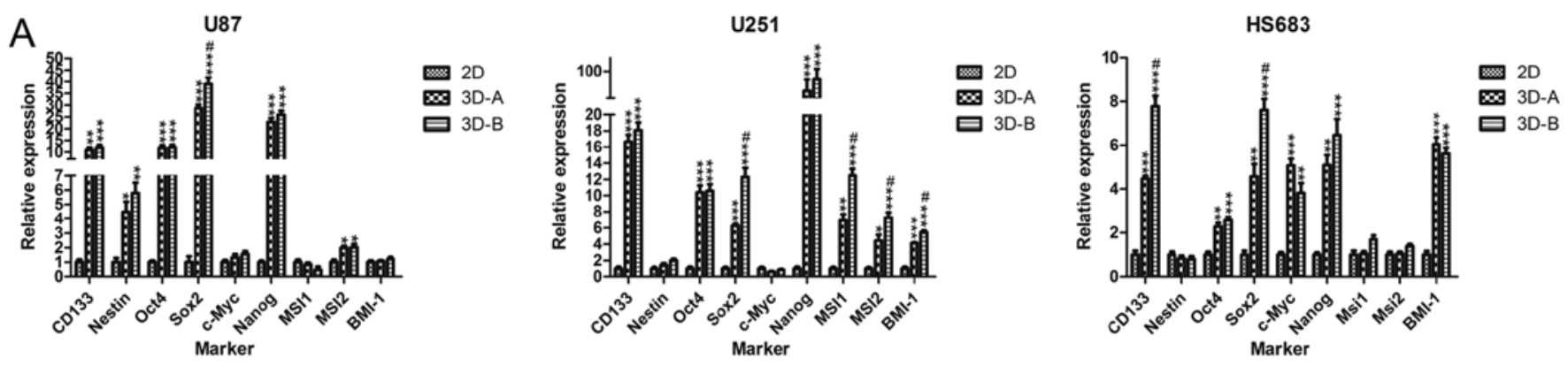

B
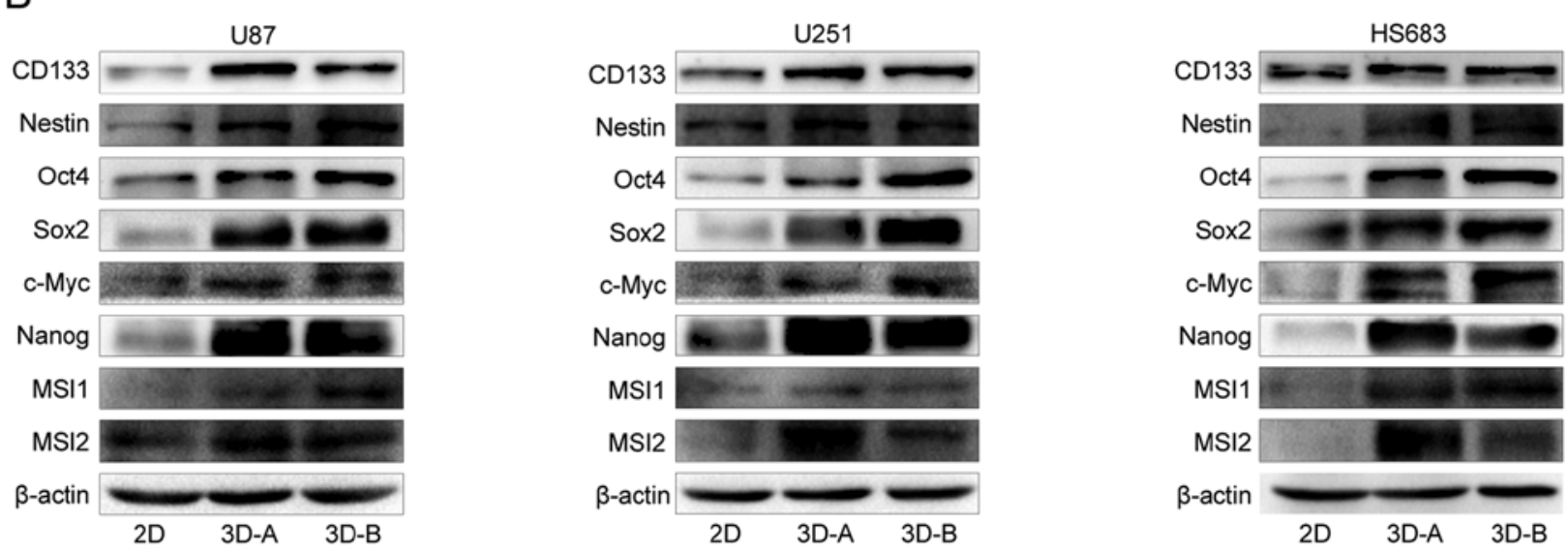

Figure 4. Expression of stemness-related genes. (A) mRNA expression levels of stem cell genes CD133, Nestin, Oct4, Sox2, c-Myc, Nanog, MSI1, MSI2 and $B M I-1$, determined by reverse transcription-quantitative polymerase chain reaction analysis. ${ }^{*} \mathrm{P}<0.05,{ }^{* * *} \mathrm{P}<0.01$ and ${ }^{* * * *} \mathrm{P}<0.001$, compared with $2 \mathrm{D}$ groups; ${ }^{\text {"}} \mathrm{P}<0.05$, compared with 3D-A groups. (B) Protein expression levels of the above stem cell genes, determined by western blot analysis. The majority of the genes were upregulated in all the three cell lines. 3D, three-dimensional; 2D, two-dimensional; Oct4, octamer-binding transcription factor 4; Sox2, SRY-Box 2; MSI, Musashi RNA binding protein.

showed a lag phase of 1-5 days and an exponential increase between 5 and 10 days. However, the cells grew more slowly in 3D scaffolds than in 2D monolayer cultures. Statistically significant differences were observed on days 5 and 10 of culture $(\mathrm{P}<0.05)$. However, there was no statistically significant difference between the scaffold A group and scaffold B group in any of the cell lines.

Changes in gene expression profiles in $3 D$ scaffold-cultured cells. The present study compared the differences in gene expression profiles between the 3D cultured cells and 2D monolayer cells using RT-qPCR and western blot analyses. The examined genes were related to stemness, cell cycle, epithelial-mesenchymal transition (EMT), migration, invasion and glioma malignancy.

The stemness-related genes, including CD133, Nestin, Oct4, Sox2, c-Myc, Nanog, MSI1, MSI2 and BMI-1, were examined. As shown in Fig. 4A, the majority of these genes were upregulated to different degrees in the glioma cells cultured in 3D collagen scaffolds, compared with those cultured on 2D plates, following culture for 10 days. The RT-qPCR analysis showed that CD133, Oct4, Sox2 and Nanog were markedly upregulated in all three of the cell lines, indicating these four genes were important in the glioma cell lines. Other genes were also upregulated in each of the cell lines. In the U87 cells, Nestin was upregulated; in U251 cells, MSII, MSI2 and BMI-1 were upregulated; in HS683 cells, $c-M y c$ and $B M I-1$ were upregulated. These changes of stemness markers were in accordance with the results of the morphological analysis. The western blot experiments (Fig. 4B) indicated that CD133, Nestin, Oct4, Sox2, Nanog and MSI2 were upregulated in all three cell lines, and the expression of MSI1 and c-Myc was increased in the HS683 cells. These results were consistent with the RT-qPCR data. Statistically significant differences were observed between the 3D cells and 2D cells for each of the glioma cell lines.

Subsequently, the present study analyzed the expression of cell cycle-related genes in the 2D and 3D cultured cells. The RT-qPCR results (Fig. 5A) indicated that the genes in all three of the glioma cell lines under 3D conditions shared similar changing trends, compared with those in the corresponding 2D cultured cells, which included significantly upregulated $p 21$ and $p 27$, but no changes in $C C N A, C C N B, C C N D$ or $C C N E$. Statistically significant differences were observed between the 3D cells and 2D cells for all three glioma cell lines. The western blot data (Fig. 5B) showed a degree of variance, compared with the RT-qPCR data. Compared with the 2D groups, the cells in 3D scaffolds exhibited upregulated $\mathrm{p} 21$ and p27, and increased levels of CCNA1, CCNB1, CCND1 and CCNE1. The differences between the RT-qPCR and western blot data suggested that the effect of the culture surroundings on cell cycle proteins may be predominantly at the posttranscriptional level. Although the cyclins (CCNA1, CCNB1, CCND1 and CCNE1) and cyclin-dependent kinase inhibitors (p21 and p27) were upregulated in the 3D culture systems, 
A

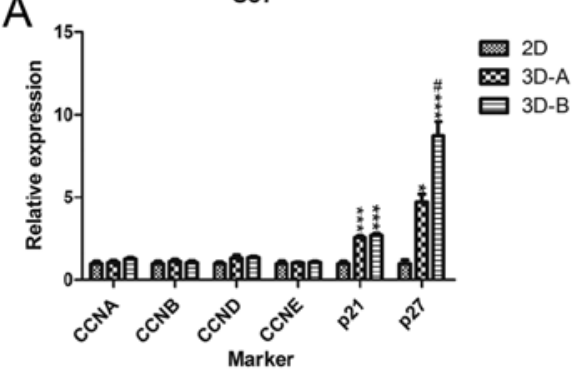

B

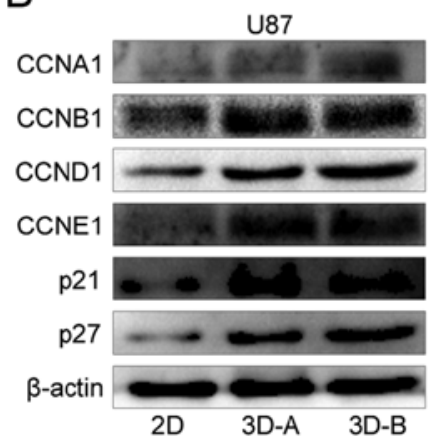

U251

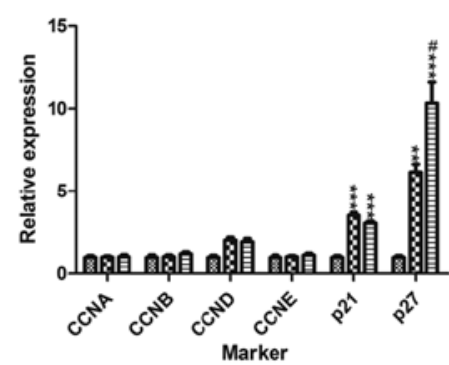

U251

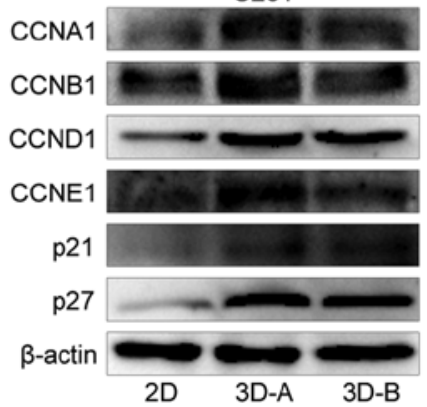

HS683
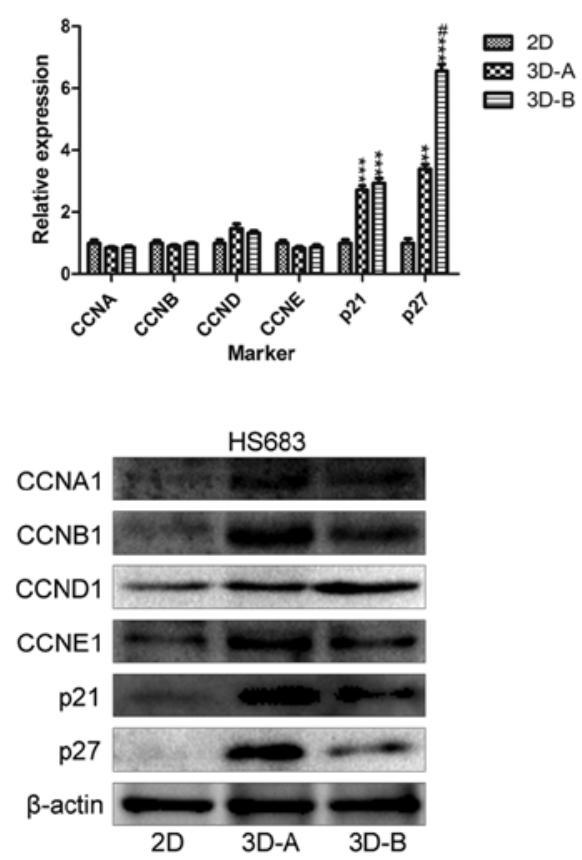

Figure 5. Expression of cell cycle-related genes. (A) mRNA expression levels of cell cycle-related genes $C C N A, C C N B, C C N D, C C N E, p 21$ and $p 27$, determined by RT-qPCR analysis. ${ }^{*} \mathrm{P}<0.05,{ }^{* *} \mathrm{P}<0.01$ and ${ }^{* * *} \mathrm{P}<0.001$, compared with $2 \mathrm{D}$ groups; ${ }^{*} \mathrm{P}<0.05$, compared with $3 \mathrm{D}-\mathrm{A}$ groups. (B) Protein expression levels of CCNA1, CCNB1, CCND1, CCNE1, p21 and p27, determined by western blot analysis. Results of RT-qPCR showed upregulated mRNA levels of $p 21$ and $p 27$, and western blot data showed higher expression of all proteins in the 3D-A group. RT-qPCR, reverse transcription-quantitative polymerase chain reaction; 3D, three-dimensional; 2D, two-dimensional; $\mathrm{CCN}$, cyclin.

their comprehensive effect was to suppress the proliferation of glioma cells, indicating that the effect of the latter was more marked.

The present study also observed the expression of genes related to EMT (N-cadherin and vimentin) and invasion (MMP1, MMP2, MMP3 and MMP7). The data are shown in Fig. 6A for RT-qPCR analysis and Fig. 6B for western blot analysis. The data obtained via RT-qPCR and western blot analyses exhibited increases in the expression of these genes to differing degrees in the 3D collagen scaffolds, compared with those in the cells cultured on $2 \mathrm{D}$ plates.

Finally, glioma malignancy-related markers, including GFAP, EGFR and Ki67, were detected. The RT-qPCR results showed that $G F A P$ and $E G F R$ were upregulated and Ki67 was downregulated in glioma cells cultured in the $3 \mathrm{D}$ system, compared with those cultured in the $2 \mathrm{D}$ system. The western blot analysis revealed similar trends (Fig. 6A and $\mathrm{B})$. These changes were concordant among the three cell lines. The upregulation of GFAP and EGFR indicated that the $3 \mathrm{D}$ collagen culture enhanced the malignancy of the glioma cells. As a tumor proliferation marker, the downregulation of Ki67 indicated the suppression of cell growth, which was consistent with the results of the cell counting and cell cycle protein assays. For the expression of all the above genes, statistically significant differences were observed between the 3D and 2D groups for each of the glioma cell lines.

Notably, in addition to the comparison between the $3 \mathrm{D}$ scaffold and the $2 \mathrm{D}$ plate groups, the expression differences of the above genes were also examined between the A-type scaffold and B-type scaffold in the three glioma cells. As indicated by the results of the RT-qPCR analysis
(Figs. 2A, 3A and 4A), common differentially expressed genes of the three cell lines were Sox 2 and p27. In the U87 and U251 cells, $N$-cadherin was the shared differential gene. GFAP was the specific differential gene for U87 cells, and $M S I 1$ and MMPI were uniquely differentially expressed in the U251 cells. These differential genes were upregulated in B-type scaffolds, compared with the A-type scaffolds. The results of the western blot analysis (Figs. 2B, 3B and 4B) showed that Oct4, Sox2, Nanog, MSI2, CCNB1, CCNE1, vimentin and GFAP were the common differential proteins to all the three cell lines. Among these proteins, the expression levels of Sox2, Oct4, vimentin and GFAP were higher in the B-type scaffold groups, and those of Nanog, MSI2, CCNB1 and CCNE1 were higher in the A-type scaffold groups. The differences between the A-type scaffold and B-type scaffold groups were significant. Compared with the results of the RT-qPCR analysis, the data from the western blot analysis showed additional differential genes and the trends were not completely the same. These data suggested that the scaffold aperture affected the gene expression of glioma cells, and that the effects were exerted mainly at the protein level rather than at the mRNA level.

Changes in the biological functions of $3 D$ system-cultured cells. Considering the variance of gene expression profiles, the present study aimed to determine whether these changes affected the relevant biological functions of glioma cells. Therefore, the colony forming ability, migratory behavior and invasive ability were compared between the 3D-scaffold cultured cells and 2D cells on plates. The analyses performed included a colony formation assay, wound-healing assay 
A

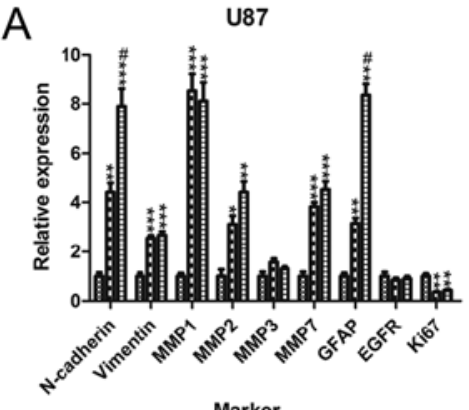

B

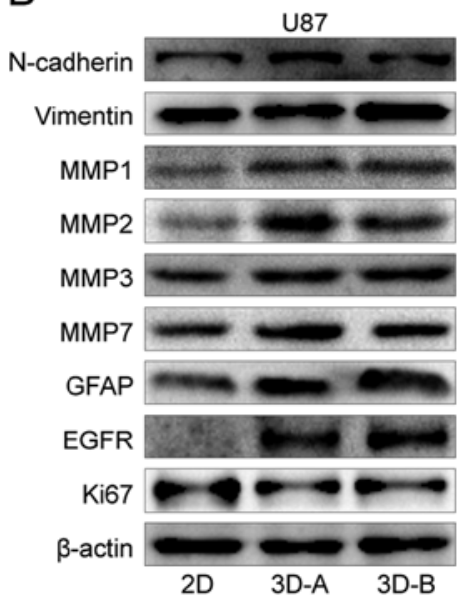

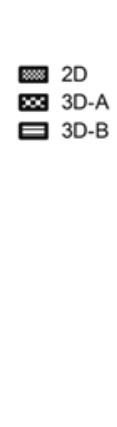
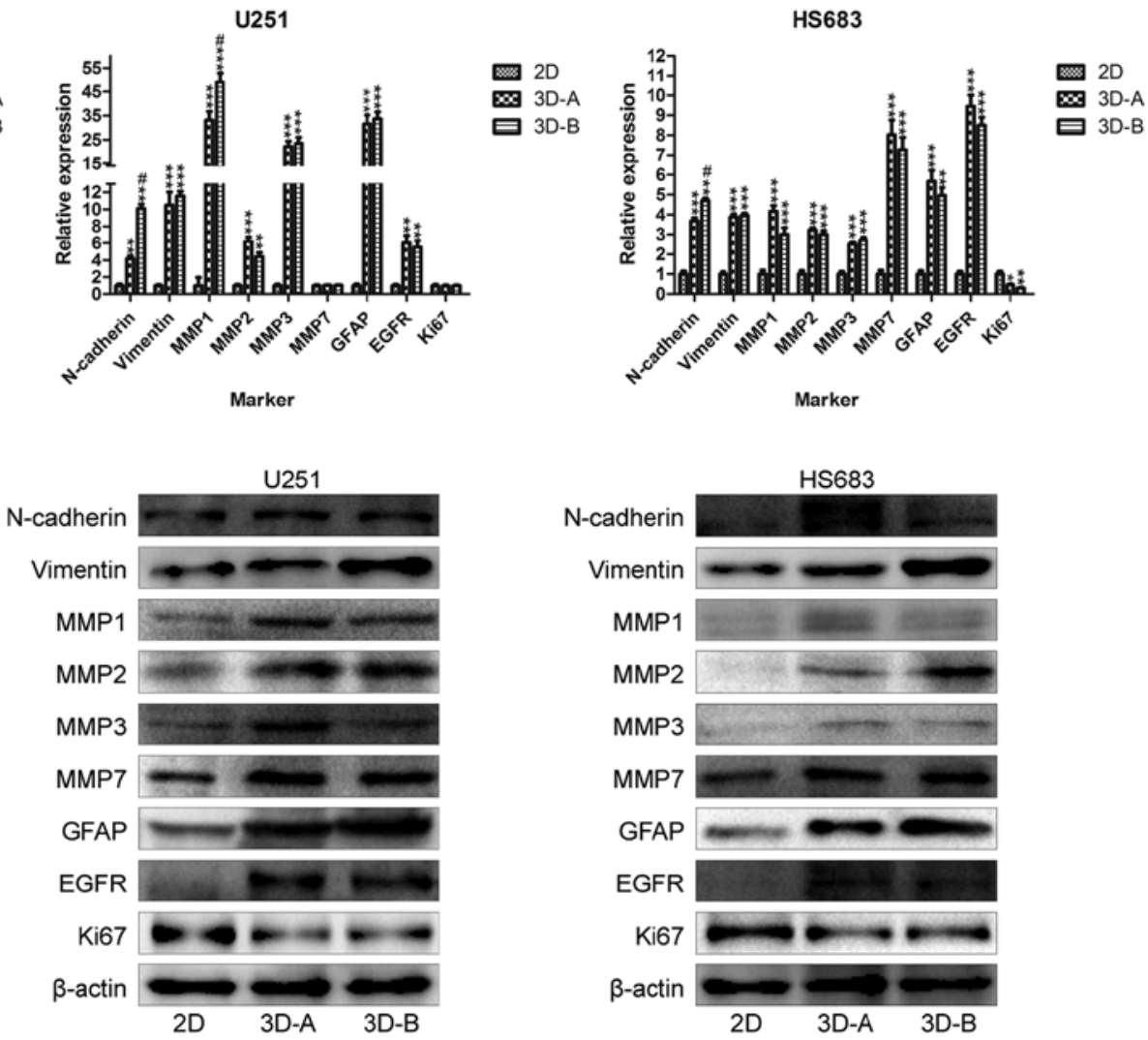

Figure 6. Expression of genes related to epithelial-mesenchymal transition, migration, invasion and glioma malignancy. (A) mRNA expression levels of genes, determined by reverse transcription-quantitative polymerase chain reaction analysis. ${ }^{*} \mathrm{P}<0.05,{ }^{* *} \mathrm{P}<0.01$ and ${ }^{* * *} \mathrm{P}<0.001$, compared with $2 \mathrm{D}$ groups; ${ }^{*} \mathrm{P}<0.05$, compared with 3D-A groups. (B) Protein expression levels of the above genes, determined by western blot analysis. These genes included $N$-cadherin, vimentin, MMP1, MMP2, MMP3, MMP7, GFAP, EGFR and Ki67. The majority of the genes were upregulated in all the three cell lines cultured in the 3D system. 3D, three-dimensional; 2D, two-dimensional; $M M P$, matrix metalloproteinase; GFAP, glial fibrillary acidic protein; EGFR, epidermal growth factor receptor.

and Transwell invasion assay. As shown in Fig. 7A and B, the cells cultured in the 3D collagen scaffolds and on the 2D plates were able to form colonies, however, more colonies were formed in all three cell lines when cultured under $3 \mathrm{D}$ conditions. The differences between the 2D cells and 3D cells were significant. Among the three cell lines, the U87 cells exhibited the most marked colony formation ability, which was consistent with the results of stemness-related gene expression. As shown in Fig. 8A and B, the 3D collagen scaffold culture environment enhanced the migration ability of the glioma cells, compared with the 2D plate culture environment for all three cell lines.

Similarly, the results of Transwell invasion assay confirmed the effects of 3D culture methods on glioma cells. As shown in Fig. 9A and B, a higher number of 3D-cultured glioma cells passed through the Matrigel matrix and appeared on the underside of the membranes. Statistically significant differences were found between the 3D cells and 2D cells for all three glioma cell lines $(\mathrm{P}<0.001)$.

In addition to the comparison between $3 \mathrm{D}$ and $2 \mathrm{D}$ cells, the differences in biological function between the A-type scaffold and B-type scaffold in glioma cells were examined. With the exception of the colony formation assay for the U87 groups, no significant differences were found in any of the functional analyses for the cell lines, although differential genes existed between the A-type scaffold and B-type scaffold. These data indicated that the aperture size of the collagen-scaffold had no clear effect on the biological functions of the glioma cells.

Changes in associated signaling pathways in $3 D$ systemcultured cells. To examine the molecular mechanisms underlying the changes in gene expression and biological functions, the present study detected typical signaling pathways using western blot analysis, including the apoptotic, Wnt, $\mathrm{SHH}$ and Notch pathways. As shown in Fig. 10A and B, compared with the 2D-cultured cells, pro-apoptotic factors, including caspases, poly (ADP-ribose) polymerase (PARP) and p53, were downregulated and anti-apoptotic factors (PDL-1 and Livin) were upregulated in cells cultured in 3D scaffolds for all three cell lines. These results suggested that the 3D culture environment inhibited the apoptosis of glioma cells. The Wnt pathway, SHH pathway and Notch pathway are three representative signal transduction pathways, which are involved in regulating multiple functions of cells and affecting the occurrence and development of glioma. Therefore, the present study also detected key proteins in these pathways. As shown in Fig. 11, Notch1, 2 and 3, Wnt3a, Wnt5a and SHH were all expressed at high levels in the three types of 3D-cultured cells, compared with those in the 2D-cultured cells, suggesting that the 3D collagen scaffold culture affected several important signaling pathways, followed by changes in gene expression and biological functions. 
A
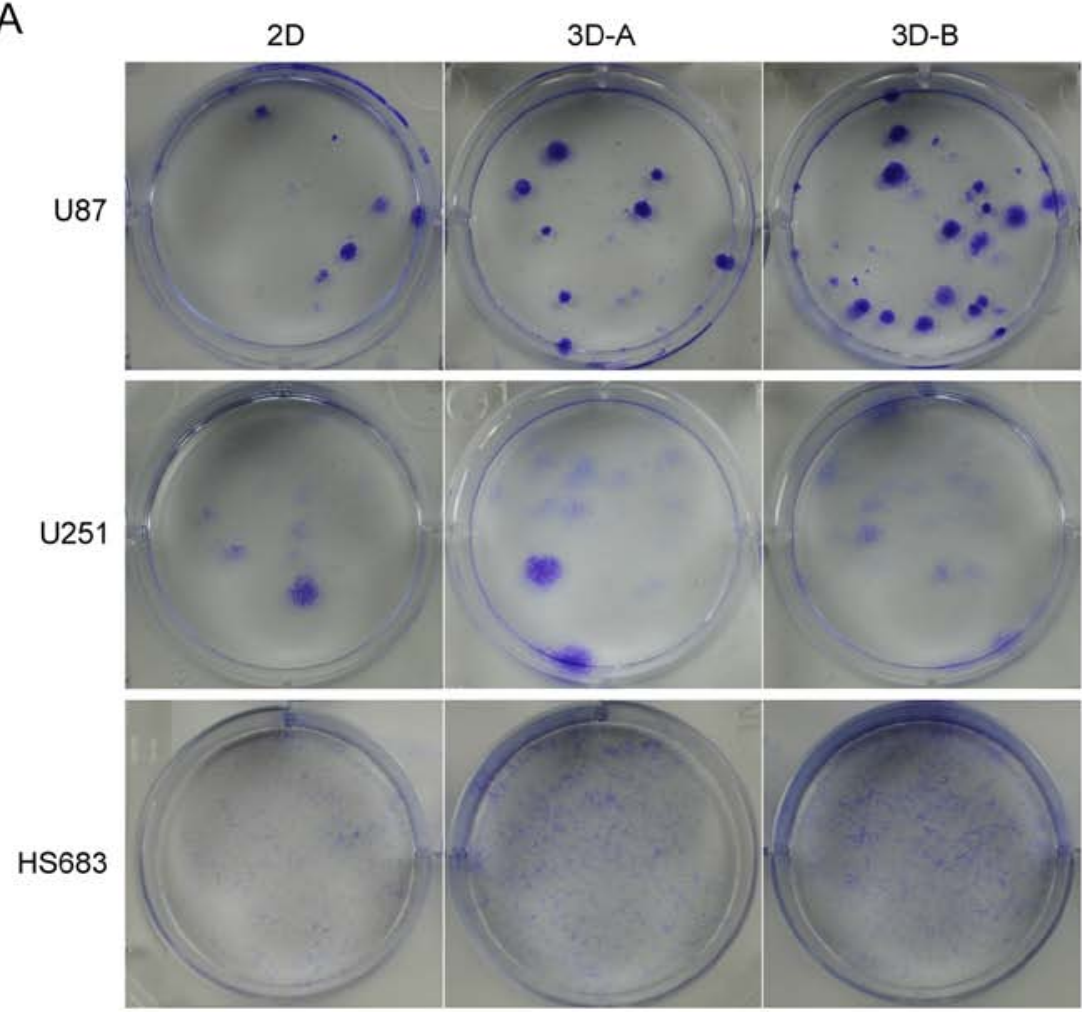

B
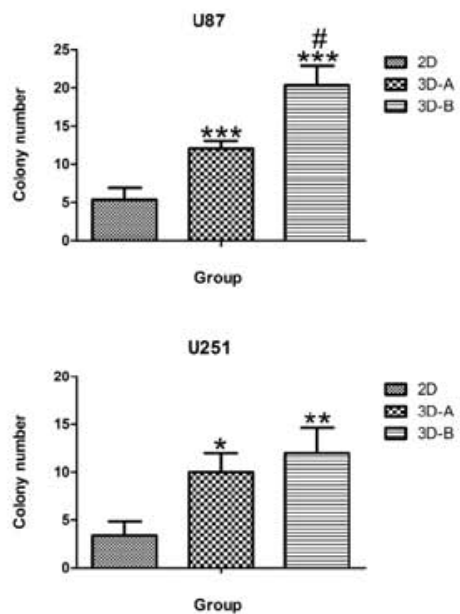

HS683

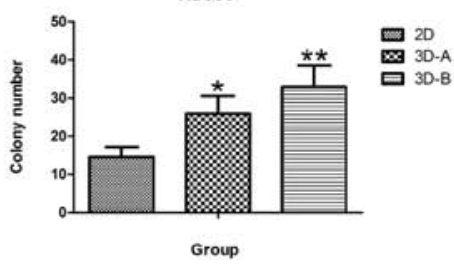

Figure 7. Colony forming ability of three glioma cells cultured under 2D and 3D conditions, determined by a colony formation assay. (A) Results of colony formation assay. (B) Statistical analysis of the results. ${ }^{*} \mathrm{P}<0.05,{ }^{* * *} \mathrm{P}<0.01$ and ${ }^{* * * *} \mathrm{P}<0.001$, compared with $2 \mathrm{D}$ groups; ${ }^{*} \mathrm{P}<0.05$, compared with $3 \mathrm{D}-\mathrm{A}$ groups More colonies were formed in all the three kinds of cells cultured under 3D conditions. With the exception of U87, no statistically significant differences were observed between the scaffold A and scaffold B groups. 3D, three-dimensional; 2D, two-dimensional.

A

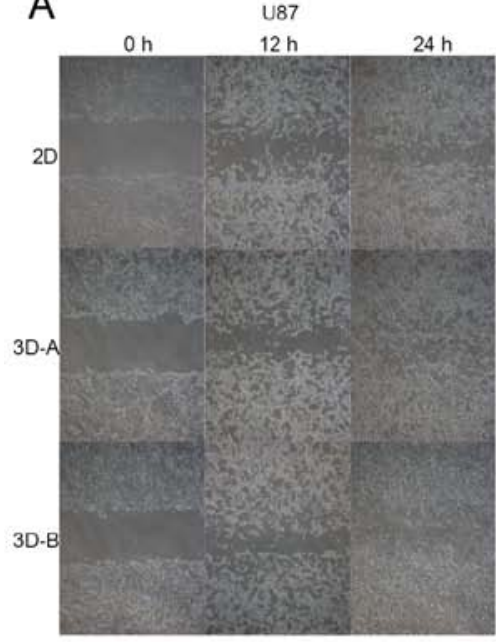

B

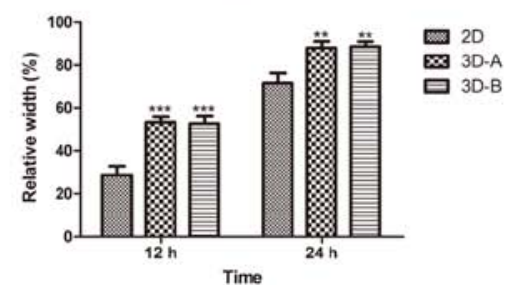

U251

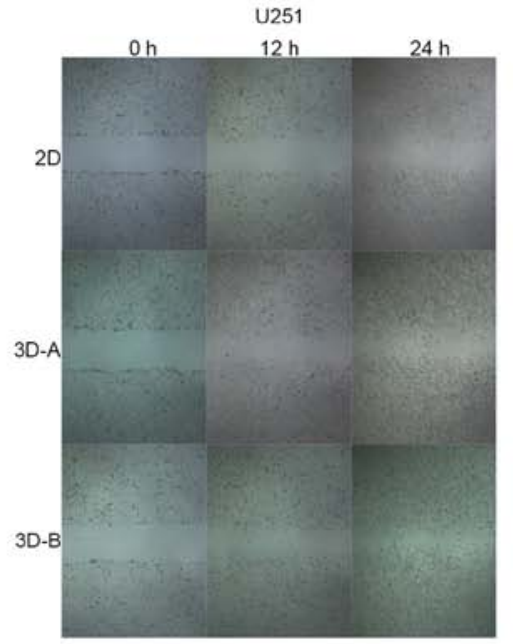

U251

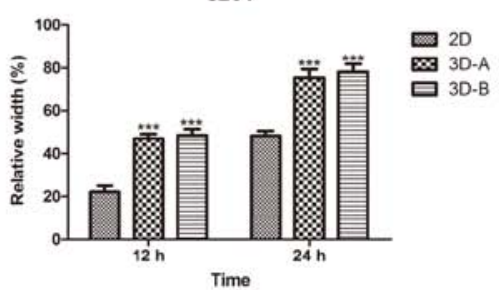

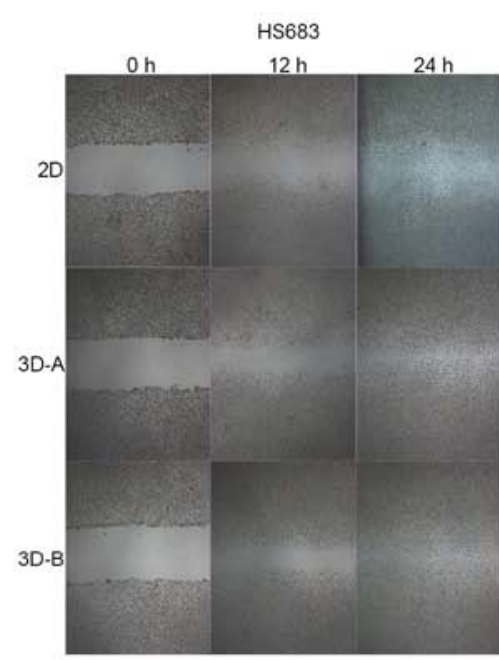

HS683

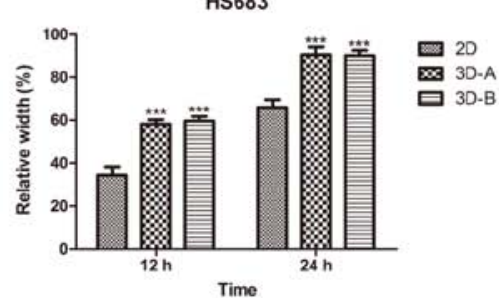

Figure 8. Migratory behavior of 2D cells on plates and 3D scaffold cultured cells, determined by a wound-healing assay. (A) Results of the wound-healing assay. (B) Statistical analysis of the results. ${ }^{* *} \mathrm{P}<0.01$ and ${ }^{* * * *} \mathrm{P}<0.001$, compared with $2 \mathrm{D}$ groups. Images were captured at 0,12 and $24 \mathrm{~h}$, and the distances between the two edges were scaled for three positions at different time-points. 3D-collagen-scaffold culture environments enhanced the migration ability of glioma cells, compared with the 2D-plate culture environment for all the three types of cell. No statistically significant differences were observed between the scaffold A and scaffold B groups. 3D, three-dimensional; 2D, two-dimensional. 
A

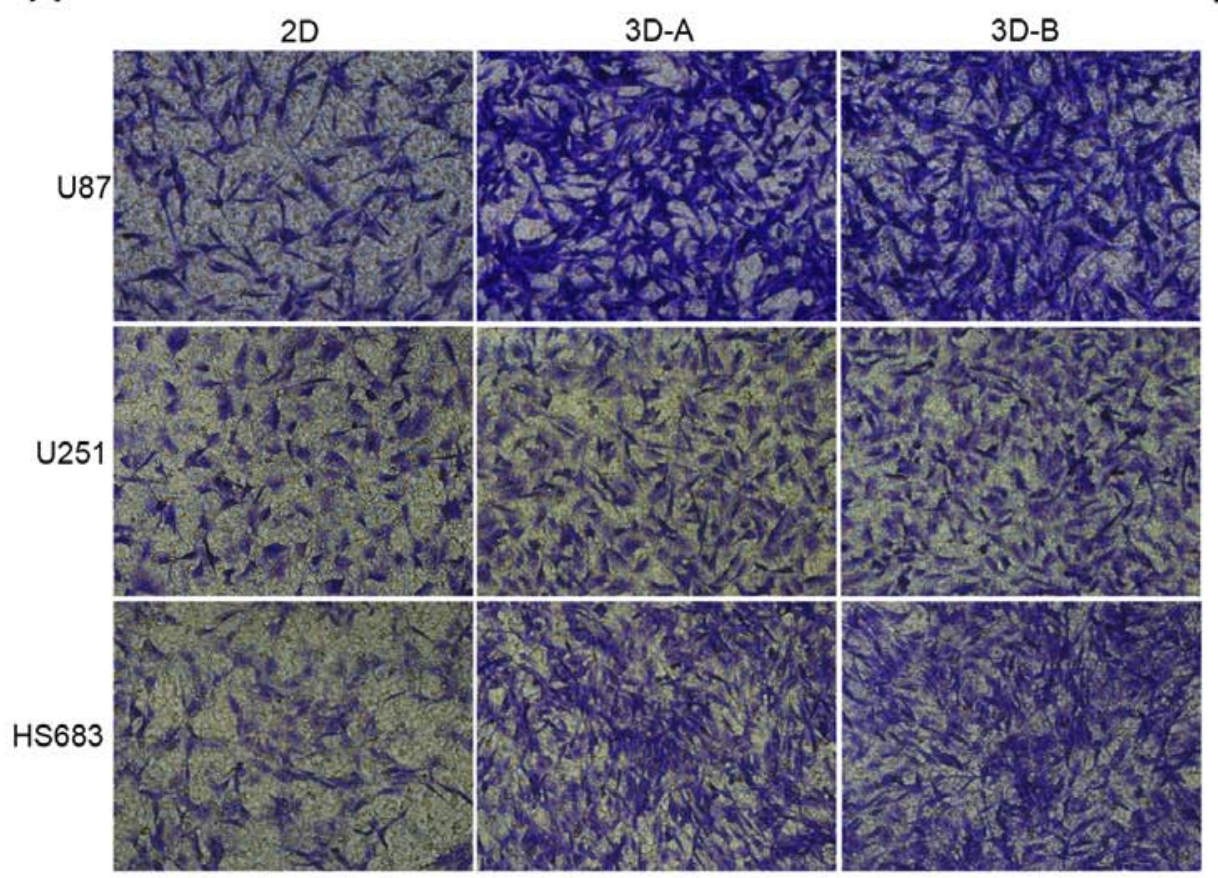

B
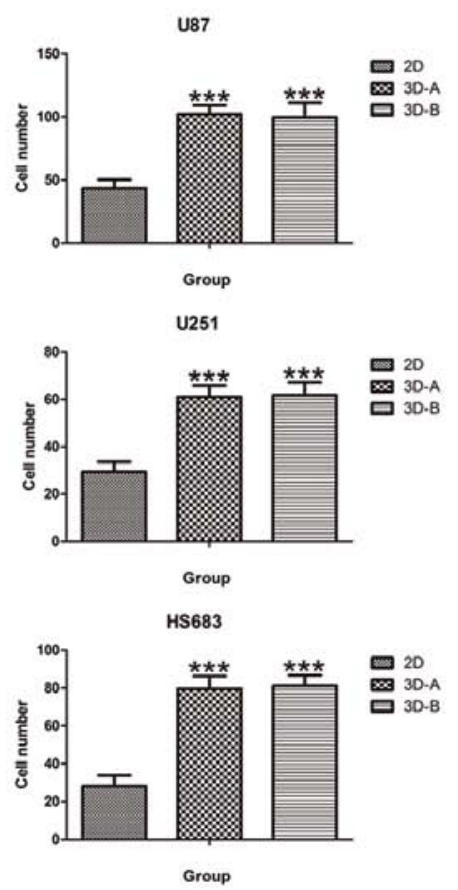

Figure 9. Invasive ability of the three glioma cells cultured under 2D and 3D conditions, determined using a Transwell invasion assay. (A) Results of Transwell invasion assay (x400 magnification). (B) Statistical analysis of the results. ${ }^{* * *} \mathrm{P}<0.001$, compared with $2 \mathrm{D}$ groups. Compared with $2 \mathrm{D}$ groups, more glioma cells passed through the Matrigel matrix and appeared on the underside of the membranes in 3D groups. No statistically significant differences were observed between the scaffold A and scaffold B groups. 3D, three-dimensional; 2D, two-dimensional.

A

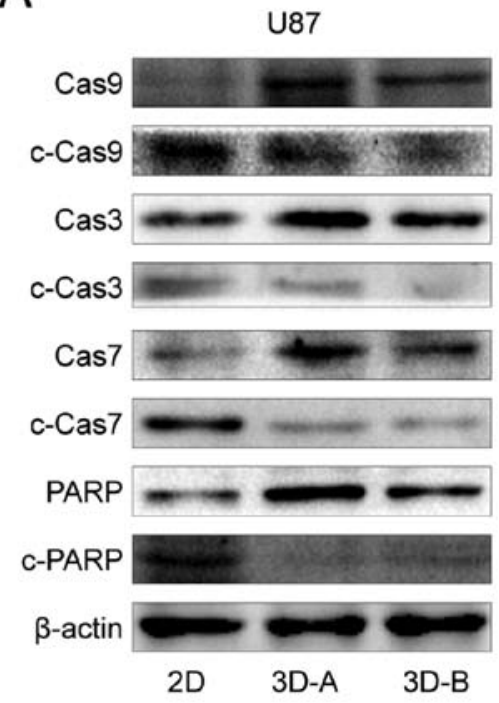

B

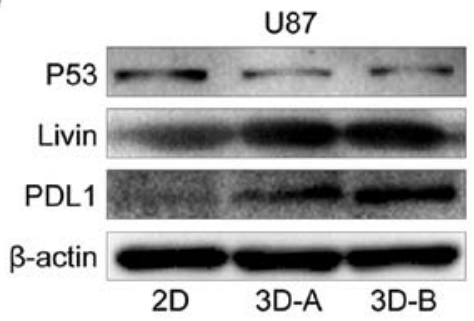

U251
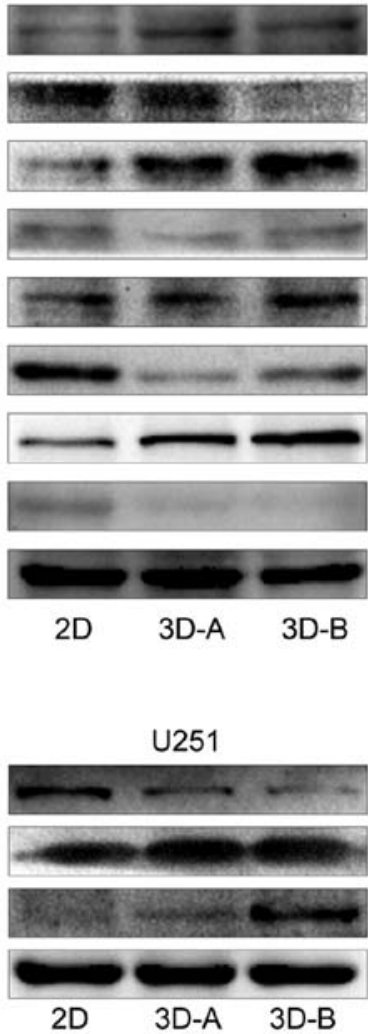

HS683

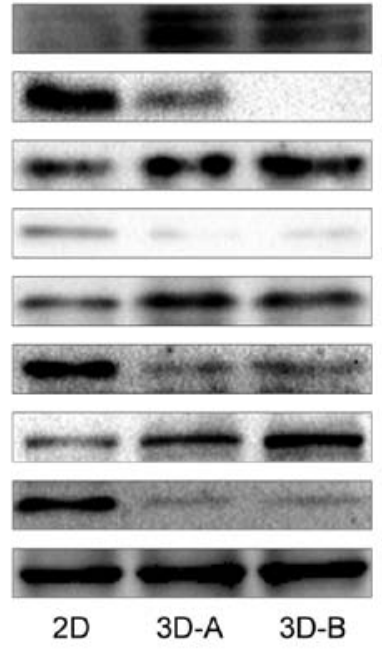

HS683

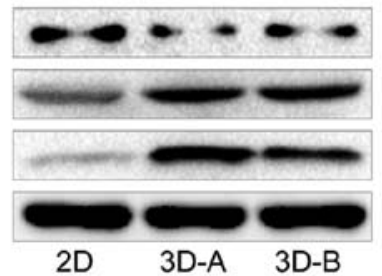

Figure 10. Expression of apoptosis-related genes, detected by western blot analysis. (A) Apoptosis pathway regulated by caspases. (B) Other apoptosis-related genes, including p53, Livin and PDL-1. Compared with 2D cells, pro-apoptotic factors (caspases, PARP and p53) were downregulated and anti-apoptotic factors (PDL-1 and Livin) were upregulated in all three cell lines cultured in 3D scaffolds. 3D, three-dimensional; 2D, two-dimensional; Cas, caspase; PARP, poly (ADP-ribose) polymerase; PDL1, programmed death-ligand 1. 
U87

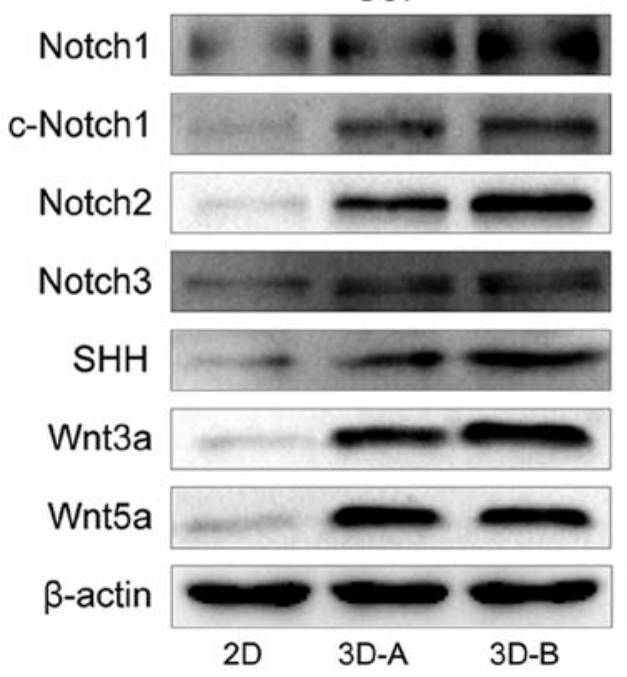

U251

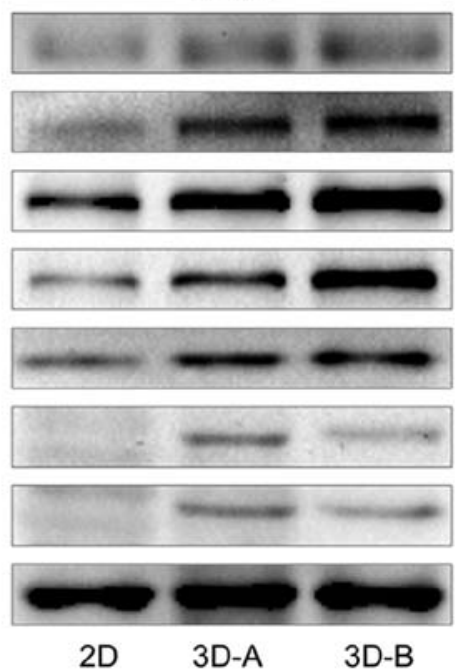

HS683

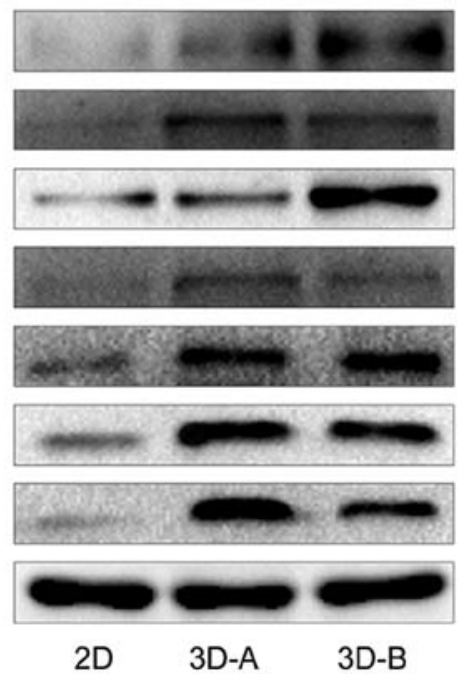

Figure 11. Expression of vital genes involved in Wnt, SHH and Notch pathways, detected by western blot analysis. Notch1, 2 and 3, Wnt3a, Wnt5a and SHH were all highly expressed at different levels in the three cell lines in the 3D cells, compared with those in the 2D cells. 3D, three-dimensional; 2D, twodimensional; SHH, Sonic Hedgehog.

The signaling differences between the A- and B-type scaffolds for all three glioma cell lines were also examined. Among apoptotic-related factors, PDL-1 was the only differential gene. It was upregulated in the B scaffold group for the U87 and U251 cells, and in the A scaffold group for the HS683 cells (Fig. 10B). For the Wnt, SHH and Notch pathways (Fig. 11), Notch2 was the common differentially expressed gene and was expressed at a high level in the B group of all three glioma cell lines. For the U87 cells, the majority of these multifunctional signaling proteins were enhanced in group B; for the U251 cells, c-Notch1 and Notch3 were increased in group B; for HS683 cells, although Notch1 and SHH were upregulated in group B, c-Notch1, Wnt3a and Wnt5a were higher in group A.

\section{Discussion}

Due to better simulating the microenvironment where in vivo cells grow, 3D culture has attracted increasing attention, and has been used in several studies of malignant tumors, including squamous cell carcinoma, pancreatic cancer and oral cancer $(8,11,12)$. 3D culture has also been used in glioma, the most common and life-threatening type of adult brain tumor. In previous studies, gels, including Matrigel or hydrogel, have been commonly used in 3D glioma culture systems (13-25). Although these systems exhibit good biocompatibility, the experimental steps of these systems are cumbersome, and the cells planted in these biomaterials show limited digestion and recycling. Therefore, 3D collagen scaffolds have become a focus of attention, not only due to their biological compatibility as a main component of the ECM, but also for the convenience of use. Previous studies have shown that rat neural stem cells, mouse embryonic stem cells and human mesenchymal stem cells grow well in this collagen scaffold, and that the stemness and self-renewal properties are maintained (31-33). However, there have been few reports on the effects of the collagen scaffold on tumor cells. Therefore, this collagen scaffold was used in the present study to observe the effect of 3D culture on glioma cells. Cell morphology and proliferation analyses indicated that the three glioma cells examined exhibited suitable biocompatibility with these $3 \mathrm{D}$ collagen scaffolds. The cells planted in collagen scaffolds formed clusters, exhibited a small and ovoid appearance, and had heteromorphic and deeply stained nuclei, indicating that co-culture with the scaffolds promoted stem cell-like changes of the glioma cells, which was coincident with the data from the previous studies mentioned.

As the effects of the collagen scaffold culture on the gene expression profile and associated functions of glioma cells remained to be fully elucidated, these alterations were systematically observed in the cells following planting in $3 \mathrm{D}$ collagen scaffolds. Compared with the $2 \mathrm{D}$ groups, the expression of stemness-related genes was increased in the $3 \mathrm{D}$ groups, consisted with the results of morphology analysis. Jiguet et al and Lv et al reported similar results $(13,17)$. The present study also surveyed other important genes involved in cell cycle, EMT, invasion and glioma malignancy. Cell cycle-related genes were upregulated to differing degrees in the 3D-cultured cells, and the comprehensive efficiency inhibited cell proliferation. The expression of the remainder of the genes also increased to differing degrees. Considering the changes in gene expression, the present study aimed to determine whether these genetic variations cause corresponding changes in biological function. The data from colony formation, wound-healing and Transwell invasion assays showed that 3D collagen culture enhanced the colonyforming, migration and invasion abilities of the glioma cells. These results suggested that the $3 \mathrm{D}$ collagen culture patterns increased the malignancy of the in vitro cultured glioma cells, and are thus closer to the environments surrounding glioma cells in vivo.

Finally, the present study examined the signaling pathways involved in these changes in gene expression and biological functions via western blot analysis. A number 
of vital pathways, including the apoptotic pathway, Wnt pathway, SHH pathway and Notch pathway, were examined. Apoptosis mediated by caspases influences cellular growth, differentiation and programmed death. The Notch, $\mathrm{SHH}$ and Wnt pathways are involved in regulating multiple functions of cells and affecting the occurrence and development of glioma (34-38). The results showed that the apoptotic pathway was inhibited, and the Notch, SHH and Wnt pathways were activated in the $3 \mathrm{D}$ culture groups for all three glioma cell lines. The data from these analyses indicated that the 3D collagen scaffold culture influenced crucial cellular signaling pathways, followed by changes in gene expression and biological functions.

In addition to the comparisons between 3D scaffold and 2D plate cultures, the present study compared the differences in the above-mentioned indicators between the A-type scaffold and B-type scaffold in the three glioma cell lines. Cell morphology and proliferation analysis showed no notable difference between the two. However, differences in gene expression were found. The differential genes included $O c t 4$, Sox2, vimentin, GFAP, Nanog, MSI2, CCNB1 and CCNE1. The expression levels of the first four of these genes were higher in the B scaffold group, whereas those of Nanog, $M S 12, C C N B 1$ and $C C N E 1$ were higher in the A scaffold group, suggesting that the large aperture collagen scaffold facilitated the expression of stemness-related and EMT genes, but that the small aperture had a more marked effect on the expression of cell cycle-related proteins. However, these differences in gene expression did not cause changes in biological functions, including clone formation, migration and invasion. Finally, the disparities in signaling pathways between the A and B-type scaffold groups were examined. Notch2 was upregulated in the B-type group for all three glioma cell lines, indicating that it was closely associated with the pore diameter of the scaffolds. For the U87 and U251 cells, the levels of the majority of these foregoing signaling proteins were increased in the B-type group. In the HS683 cells, the expression levels of certain genes, including Notch1 and SHH, were higher in the B-type group, whereas others, including c-North1, Wnt3a and Wnt5a, were higher in the A-type group. These differences among the cell lines may be due to the degree of malignancy of the cells. The highly malignant U87 and U251 glioma cells in the collagen scaffolds grow in clumps more readily, owing to their adhesion and proliferation abilities, therefore, the large aperture may be more appropriate for these cells and induce increased activity in the signaling pathways. As a less malignant glioma cell, HS683 cells in collagen scaffolds grow preferentially along the skeleton rather than in clusters, with lower adhesion and proliferation abilities; therefore the advantage of the large aperture in activating the signaling pathways was less apparent. The results of the H\&E staining were in accordance with these hypotheses.

Notably, we used the controversial U87 MG ATCC (American Type Culture Collection, Manassas, VA, USA) cell line in the present study according to the STR profile test performed by us (data not shown). In the past, the U87 cell line from ATCC was widely applied in studies on glioma as a glioblastoma cell line. However, Allen et al reported that this cell line from ATCC was not the original glioblastoma cell line established in 1968 at the University of Uppsala, and it was most probably also a glioblastoma cell line, but whose origin was unknown (39). As we were concerned that the misidentification of the U87 MG ATCC cell line might affect the outcomes of the present study, in this study, we observed the cell morphology and gene expression profile of the U87 MG ATCC cells and the results revealed that these cells exhibited the characteristics of glioblastoma. Furthermore, following implantation in 3D collagen scaffolds, the U87 MG ATCC cell groups exhibited similar changes as the U251 cell groups (another high-grade glioma cell line) and exhibited a greater malignancy than the low-grade glioma cell line (HS683), not only from the gene expression analysis, but also from the corresponding biological function analysis. These data indicated that this misidentification may not affect the outcomes of the present study. In conclusion, the present study found that 3D collagen scaffolds had good biocompatibility with glioma cells, and enhanced the malignancy of the glioma cells by affecting gene expression and biological functions. The increase in the degree of malignancy was regulated by several signal transduction pathways, including the apoptotic, Wnt, SHH and Notch pathways. The in vitro glioma culture models based on 3D collagen scaffolds may better reflect the characteristics of in vivo tumor growth and have widespread application potential as platforms for screening novel anti-glioma therapeutics.

\section{Acknowledgements}

The authors gratefully acknowledge the cooperation of all participating institutes for experimental technical support.

\section{Funding}

The present study was supported by the National Key Research and Development Program of China (grant no. 2016YFC1101502), the National Natural Science Foundation of China (grant nos. 81472355, 81773179 and 81272972), the Strategic Priority Research Program of the Chinese Academy of Sciences (grant no. XDA01030000), the Hunan Provincial Science and Technology Department (grant nos. 2014FJ6006 and 2016JC2049) and the Open-End Fund for the Valuable and Precision Instruments of Central South University (grant no. SUZC201634 and CSUZC201638).

\section{Availability of data and materials}

All the data supporting the conclusions of this article are included in the article.

\section{Authors' contributions}

WJ performed the major experiments and wrote the manuscript. CR, XJ and JD contributed equally to the conception and design of the study proposal. JD prepared the collagen scaffolds. WL and CR revised the manuscript. WL, LW, BZ, $\mathrm{WH}$ and $\mathrm{WJ}$ directed the writing and layout of the manuscript. SL and XL contributed to data analysis. XZ and DC reviewed the manuscript and provided suggestions. HZ, XL, MZ and DX provided experimental technical support. 


\section{Ethics approval and consent to participate}

Not applicable.

\section{Consent for publication}

Not applicable.

\section{Competing interests}

The authors declare that there are no competing interests.

\section{References}

1. Ostrom QT, Gittleman H, Liao P, Rouse C, Chen Y, Dowling J, Wolinsky Y, Kruchko C and Barnholtz-Sloan J: CBTRUS statistical report: Primary brain and central nervous system tumors diagnosed in the United States in 2007-2011. Neuro Oncol 16 (Suppl 4): iv1-iv63, 2014.

2. Hong J, Peng Y, Liao Y, Jiang W, Wei R, Huo L, Han Z, Duan C and Zhong M: Nimotuzumab prolongs survival in patients with malignant gliomas: A phase I/II clinical study of concomitant radiochemotherapy with or without nimotuzumab. Exp Ther Med 4: 151-157, 2012

3. Louis DN, Perry A, Reifenberger G, von Deimling A, FigarellaBranger D, Cavenee WK, Ohgaki H, Wiestler OD, Kleihues P and Ellison DW: The 2016 World Health Organization Classification of Tumors of the Central Nervous System: A summary. Acta Neuropathol 131: 803-820, 2016.

4. Birgersdotter A, Sandberg R and Ernberg I: Gene expression perturbation in vitro - a growing case for three-dimensional (3D) culture systems. Semin Cancer Biol 15: 405-412, 2005.

5. Fallica B, Makin G and Zaman MH: Bioengineering approaches to study multidrug resistance in tumor cells. Integr Biol 3: 529-539, 2011.

6. Shannon S, Vaca C, Jia D, Entersz I, Schaer A, Carcione J, Weaver M, Avidar Y, Pettit R, Nair M, et al: Dexamethasonemediated activation of fibronectin matrix assembly reduces dispersal of primary human glioblastoma cells. PLoS One 10: e0135951, 2015.

7. Le HT, Nguyen HT, Min HY, Hyun SY, Kwon S, Lee Y, Le THV, Lee J, Park JH and Lee HY: Panaxynol, a natural Hsp90 inhibitor, effectively targets both lung cancer stem and non-stem cells. Cancer Lett 412: 297-307, 2018.

8. Jiang YJ, Lee CL, Wang Q, Zhou ZW, Yang F, Jin C and Fu DL: Establishment of an orthotopic pancreatic cancer mouse model: Cells suspended and injected in Matrigel. World J Gastroenterol 20: 9476-9485, 2014.

9. Jiang Z, Han B, Li H, Li X, Yang Y and Liu W: Preparation and anti-tumor metastasis of carboxymethyl chitosan. Carbohydr Polym 125: 53-60, 2015.

10. Wang X, Shi L, Tu Q, Wang H, Zhang H, Wang P, Zhang L, Huang Z, Zhao F, Luan $\mathrm{H}$, et al: Treating cutaneous squamous cell carcinoma using 5-aminolevulinic acid polylactic-co-glycolic acid nanoparticle-mediated photodynamic therapy in a mouse model. Int J Nanomedicine 10: 347-355, 2015.

11. Yu L, Ni C, Grist SM, Bayly C and Cheung KC: Alginate coreshell beads for simplified three-dimensional tumor spheroid culture and drug screening. Biomed Microdevices 17: 33 , 2015.

12. Sakuma K, Tanaka A and Mataga I: Collagen gel dropletembedded culture drug sensitivity testing in squamous cell carcinoma cell lines derived from human oral cancers: Optimal contact concentrations of cisplatin and fluorouracil. Oncol Lett 12: 4643-4650, 2016.

13. Jiguet Jiglaire C, Baeza-Kallee N, Denicolaï E, Barets D, Metellus P, Padovani L, Chinot O, Figarella-Branger D and Fernandez C: Ex vivo cultures of glioblastoma in three-dimensional hydrogel maintain the original tumor growth behavior and are suitable for preclinical drug and radiation sensitivity screening. Exp Cell Res 321: 99-108, 2014.

14. Bayat N, Ebrahimi-Barough S, Norouzi-Javidan A, Saberi H, Tajerian R, Ardakan MMM, Shirian S, Ai A and Ai J: Apoptotic effect of atorvastatin in glioblastoma spheroids tumor cultured in fibrin gel. Biomed Pharmacother 84: 1959-1966, 2016.
15. Fan Y, Nguyen DT, Akay Y, Xu F and Akay M: Engineering a brain cancer chip for high-throughput drug screening. Sci Rep 6: 25062, 2016.

16. Heffernan JM, Overstreet DJ, Srinivasan S, Le LD, Vernon BL and Sirianni RW: Temperature responsive hydrogels enable transient three-dimensional tumor cultures via rapid cell recovery. J Biomed Mater Res A 104: 17-25, 2016.

17. Lv D, Yu SC, Ping YF, Wu H, Zhao X, Zhang H, Cui Y, Chen B Zhang X, Dai J, et al: A three-dimensional collagen scaffold cell culture system for screening anti-glioma therapeutics. Oncotarget 7: 56904-56914, 2016.

18. Wang K, Kievit FM, Erickson AE, Silber JR, Ellenbogen RG and Zhang M: Culture on 3D chitosan-hyaluronic acid scaffolds enhances stem cell marker expression and drug resistance in human glioblastoma cancer stem cells. Adv Healthc Mater 5: 3173-3181, 2016

19. Gonçalves DPN, Rodriguez RD, Kurth T, Bray LJ, Binner M, Jungnickel C, Gür FN, Poser SW, Schmidt TL, Zahn DRT, et al: Enhanced targeting of invasive glioblastoma cells by peptidefunctionalized gold nanorods in hydrogel-based 3D cultures. Acta Biomater 58: 12-25, 2017.

20. Gomez-Roman N, Stevenson K, Gilmour L, Hamilton G and Chalmers AJ: A novel 3D human glioblastoma cell culture system for modeling drug and radiation responses. Neuro Oncol 19: 229-241, 2017.

21. Heffernan JM, McNamara JB, Borwege S, Vernon BL, Sanai N, Mehta S and Sirianni RW: PNIPAAm-co-Jeffamine ${ }^{\circledR}(\mathrm{PNJ})$ scaffolds as in vitro models for niche enrichment of glioblastoma stem-like cells. Biomaterials 143: 149-158, 2017.

22. Narayan RS, Fedrigo CA, Brands E, Dik R, Stalpers LJ, Baumert BG, Slotman BJ, Westerman BA, Peters GJ and Sminia P: The allosteric AKT inhibitor MK2206 shows a synergistic interaction with chemotherapy and radiotherapy in glioblastoma spheroid cultures. BMC Cancer 17: 204, 2017.

23. Pedron S, Hanselman JS, Schroeder MA, Sarkaria JN and Harley BAC: Extracellular hyaluronic acid influences the rfficacy of EGFR tyrosine kinase inhibitors in a biomaterial model of glioblastoma. Adv Healthc Mater 6: 1700529, 2017.

24. Schiariti MP, Restelli F, Ferroli P, Benetti A, Berenzi A, Ferri A, Ceserani V, Ciusani E, Cadei M, Finocchiaro G, et al: Fibronectin-adherent peripheral blood derived mononuclear cells as Paclitaxel carriers for glioblastoma treatment: An in vitro study. Cytotherapy 19: 721-734, 2017.

25. Wang C, Tong X, Jiang X and Yang F: Effect of matrix metalloproteinase-mediated matrix degradation on glioblastoma cell behavior in 3D PEG-based hydrogels. J Biomed Mater Res A 105: 770-778, 2017.

26. Chen L, Xiao Z, Meng Y, Zhao Y, Han J, Su G, Chen B and Dai J: The enhancement of cancer stem cell properties of MCF-7 cells in 3D collagen scaffolds for modeling of cancer and anti-cancer drugs. Biomaterials 33: 1437-1444, 2012.

27. Liu H, Ren C, Zhu B, Wang L, Liu W, Shi J, Lin J, Xia X, Zeng F, Chen J, et al: High-efficient transfection of human embryonic stem cells by single-cell plating and starvation. Stem Cells Dev 25: 477-491, 2016.

28. Schmittgen TD and Livak KJ: Analyzing real-time PCR data by the comparative C(T) method. Nat Protoc 3: 1101-1108, 2008.

29. Huang W, Liu J, Feng X, Chen H, Zeng L, Huang G, Liu W, Wang L, Jia W, Chen J, et al: DLC-1 induces mitochondrial apoptosis and epithelial mesenchymal transition arrest in nasopharyngeal carcinoma by targeting EGFR/Akt/NF- $\kappa$ B pathway. Med Oncol 32: 115, 2015

30. Feng X, Li C, Liu W, Chen H, Zhou W, Wang L, Zhu B, Yao K, Jiang $X$ and Ren C: DLC-1, a candidate tumor suppressor gene, inhibits the proliferation, migration and tumorigenicity of human nasopharyngeal carcinoma cells. Int J Oncol 42: 1973-1984, 2013.

31. Cui Y, Xiao Z, Chen T, Wei J, Chen L, Liu L, Chen B, Wang X, Li $X$ and Dai J: The miR-7 identified from collagen biomaterialbased three-dimensional cultured cells regulates neural stem cell differentiation. Stem Cells Dev 23: 393-405, 2014.

32. Du M, Liang H, Mou C, Li X, Sun J, Zhuang Y, Xiao Z, Chen B and Dai J: Regulation of human mesenchymal stem cells differentiation into chondrocytes in extracellular matrix-based hydrogel scaffolds. Colloids Surf B Biointerfaces 114: 316-323, 2014.

33. Wei J, Han J, Zhao Y, Cui Y, Wang B, Xiao Z, Chen B and Dai J: The importance of three-dimensional scaffold structure on stemness maintenance of mouse embryonic stem cells. Biomaterials 35: 7724-7733, 2014. 
34. Filbin MG, Dabral SK, Pazyra-Murphy MF, Ramkissoon S, Kung AL, Pak E, Chung J, Theisen MA, Sun Y, Franchetti Y, et al: Coordinate activation of Shh and PI3K signaling in PTENdeficient glioblastoma: New therapeutic opportunities. Nat Med 19: 1518-1523, 2013.

35. Borcherding N, Kusner D, Kolb R, Xie Q, Li W, Yuan F, Velez G, Askeland R, Weigel RJ and Zhang W: Paracrine WNT5A signaling inhibits expansion of tumor-initiating cells. Cancer Res 75: 1972-1982, 2015.

36. Tian J, He H and Lei G: Wnt/ $/ 3$-catenin pathway in bone cancers. Tumour Biol 35: 9439-9445, 2014

37. Zong D, Ouyang R, Li J, Chen Y and Chen P: Notch signaling in lung diseases: Focus on Notch1 and Notch3. Ther Adv Respir Dis 10: 468-484, 2016.
38. Liu L, Yang ZL, Wang C, Miao X, Liu Z, Li D, Zou Q, Li J, Liang L, Zeng G, et al: The Expression of Notch 1 and Notch 3 in gallbladder cancer and their clinicopathological significance. Pathol Oncol Res 22: 483-492, 2016.

39. Allen M, Bjerke M, Edlund H, Nelander S and Westermark B: Origin of the U87MG glioma cell line: Good news and bad news. Sci Transl Med 8: 354re3, 2016.

\footnotetext{
(i) (8) This work is licensed under a Creative Commons Attribution-NonCommercial-NoDerivatives 4.0 International (CC BY-NC-ND 4.0) License.
} 